\title{
Distribution, habitat and status of the new species Nonggang Babbler Stachyris nonggangensis
}

\author{
LI ZHAOTIAN, ZHOU FANG, LU ZHOU, JIANG AIWU, YANG GANG and \\ YU CHENXING
}

\section{Summary}

The Nonggang Babbler Stachyris nonggangensis is a new species of Timaliidae which was discovered in the Sino-Vietnamese border region in 2008. The species was initially classified as "Near Threatened" on the IUCN Red List and was believed to occur only in Nonggang Nature Reserve, where the type specimen was collected and where c.20o individuals were recorded. These few observations, and suggestions of a declining population, prompted us to initiate an extensive survey over the whole potential distribution range of this species in China from June 2009 to May 2011, during both dry and wet seasons. We conducted the survey in Guangxi Zhuang Autonomous Region and Yunnan Province and selected 19 reserves and forest areas where similar habitat to that in the Nonggang Reserve is known to occur. We used transects combined with playback to survey for this species. Nonggang Babbler was recorded at four new sites in the SinoVietnamese border region: two areas of the Nonggang Reserve (Nonggang and Longhu), Bangliang Gibbon Nature Reserve and Chunxiu Nature Reserve. The estimated population size of Nonggang Babbler was about 1,300 individuals in the four sites. Nonggang Babbler is also assumed to occur in the Trung Khanh Gibbon Reserve of Vietnam which adjoins Bangliang Gibbon Reserve. The estimated population in Trung Khanh is c.20o individuals. In total we estimate that the global population size of Nonggang Babbler is c.1,50o individuals. The Nonggang Babbler is restricted to karst forests, and its activities, foraging and nesting strictly rely on this habitat. Habitat loss and fragmentation are the main threats.

\section{Introduction}

The Nonggang Babbler Stachyris nonggangensis is a new species in the family Timaliidae (Zhou and Jiang 2008). Not long after being found, it was listed as "Near Threatened" (IUCN 2010) because of its narrow distribution and loss of habitat. At that time, the known distribution of Nonggang Babbler was limited to sites within the Nonggang National Nature Reserve (Nonggang NNR), China, which is located in the Sino-Vietnamese border region at $22^{\circ} 13^{\prime}-22^{\circ} 34^{\prime} \mathrm{N}$, $106^{\circ} 42^{\prime}-107^{\circ} 5^{\prime} \mathrm{E}$. As a new species, information on the distribution and habitats of Nonggang Babbler came mainly from observations at the Nonggang site. The first specimen was collected there in rainforest, and the estimated population size was approximately 1oo pairs (Zhou and Jiang 2008).

Nonggang NNR is situated in an area of typical limestone karst and Nonggang Babbler is confined to this area, but it was unclear whether this species was limited solely to limestone. In the south of Guangxi Province, there are many karst mountains with habitats that are similar to Nonggang NNR so this species could be more widespread than previously thought. It was also unclear which threats this species faced. In order to determine whether the babbler occurred 
elsewhere, we undertook field surveys in the limestone areas of south-west Guangxi Zhuang Autonomous Region and Yunnan Province in the Sino-Vietnamese border region, between June 2009 and May 2011.

\section{Methods}

\section{Study area}

The Nonggang Babbler has only been observed in habitats characterised by forest with a welldeveloped understorey. We obtained forest cover information from maps (Guangxi and Yunnan Provincial Forestry Departments and Google Earth), and found that densely vegetated and larger forest areas were located mainly within nature reserves. We therefore restricted our surveys to nature reserves and a forestry plantation in this area $\left(22^{\circ} 9^{\prime}-23^{\circ} 41^{\prime} \mathrm{N}, 105^{\circ} 29^{\prime}-108^{\circ} 6^{\prime} \mathrm{E}\right.$; Figure 1$)$. The Trung Khanh Gibbon Nature Reserve in Vietnam adjoins Bangliang Gibbon Nature Reserve and contains similar habitats. We did not conduct surveys in the Trung Khanh Reserve, but we regard the two nature reserves as one entity.

In total we surveyed 19 sites, including Nonggang Nature Reserve (divided into three sites), 15 other nature reserves and one forestry farm. Each had similar habitats to Nonggang Reserve (Figure 1 and Table 1 ).

\section{Field methods}

Fieldwork was carried out between June 2009 and May 2011 (Table 1). At each site, we established six line transects which were at least $3.5 \mathrm{~km}$ in length (measured by a handheld GPS device) and established playback/observation points every $500 \mathrm{~m}$ along these routes. These transects were walked between 06 hoo and 10hoo, and between 15 hoo and 18hoo, and all Nonggang Babblers encountered within $100 \mathrm{~m}$ either side of the route were recorded. Previous work showed that Nonggang Babbler responds consistently and vigorously to playback of an excitement call by flying to the lure and calling back. We recorded Nonggang Babbler calls using a SONY TCM50oEV tape recorder (90-900 HZ) and Sennheiser ME66 (40-2000 HZ) directional microphone. In order to collect data on numbers at each point, we used these recorded calls to attract birds towards the observer. Tape luring was carried out under licence from the reserve management, and we followed standard guidelines for this operation (Parker 1991, Antongiovanni and Metzger 2005, Summers and Buckland 2010).

Using an external amplifier the pre-recorded vocalisations of Nonggang Babbler were played at each observation point continuously for at least 10 minutes in the four cardinal directions (2.5 minutes per direction), followed by a 3-minute listening interval (Parker 1991, Antongiovanni and Metzger 2005, Summers and Buckland 2010). At each sampling point, the vocalisation was played continuously for at least 10 minutes in the four cardinal directions (2.5 minutes per direction), followed by a 3-minute listening interval. As Nonggang Babbler is vulnerable to being scared away by loud tape lures (Zhou and Jiang 2008), the sound volume was set low for the first 20-30 seconds so as not to scare any birds that were close by, and was increased to stimulate birds within a radius of about $100 \mathrm{~m}$. When responding birds arrived at the survey point, other observers counted the number of Nonggang Babblers and also recorded vegetation structure, any evidence of human interference, and other bird species. Days with persistent rain and strong wind were avoided.

Of the 19 sites surveyed, Tuoniangjiang Nature Reserve and Gulinjing Nature Reserve are located in Yunnan Province and the other sites are in Guangxi Zhuang Autonomous Region (Figure 1). Nonggang Nature Reserve consists of three isolated areas and we surveyed these separately. Among the 19 sites, 13 consist of karst, three consist mainly of sandstone landforms and the other three sites are both sandstone and shale landform and small areas of karst (Table 1 ). 


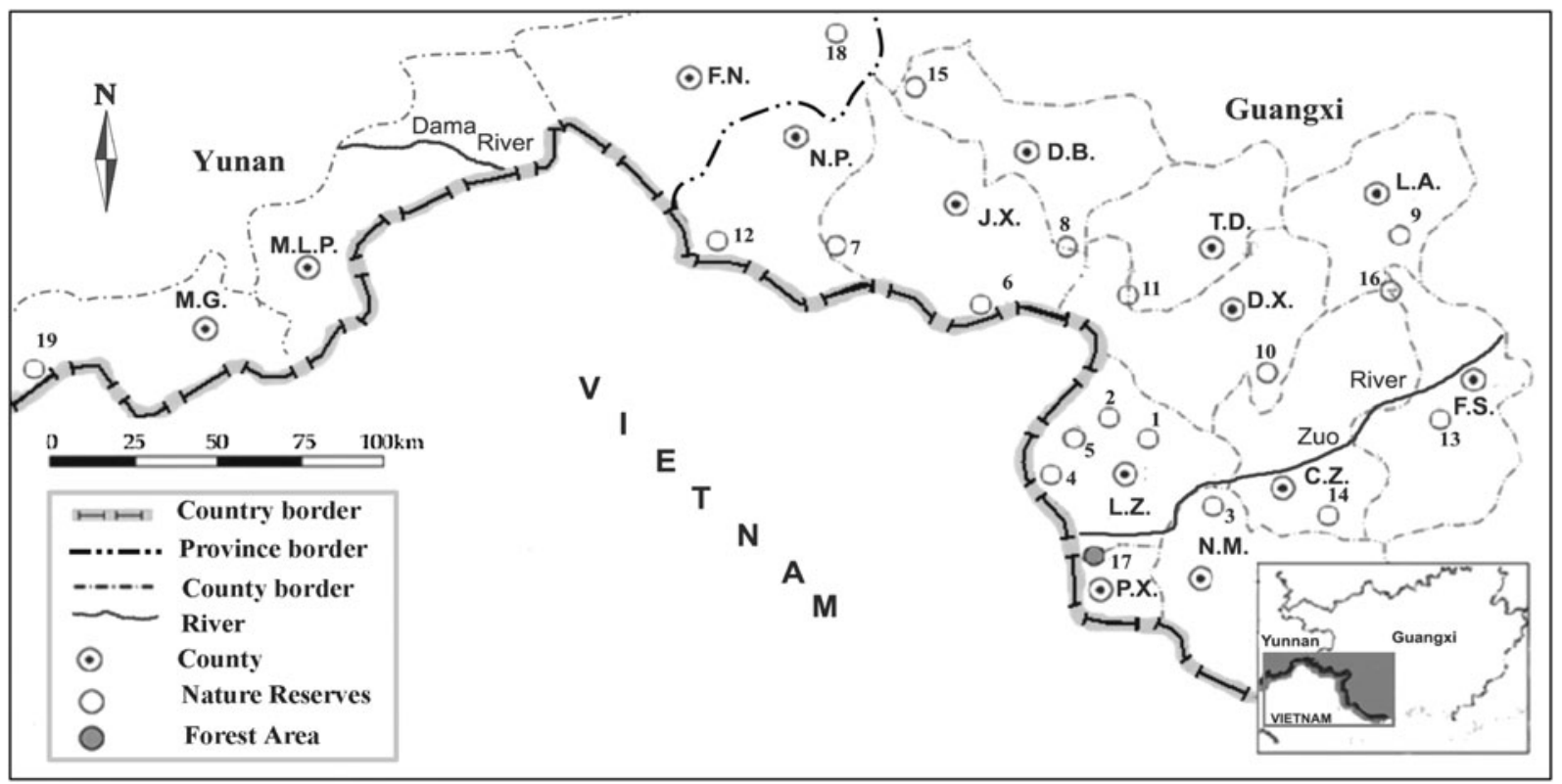

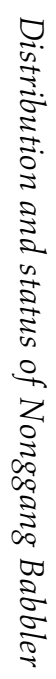

Figure 1. The study area for the Nonggang Babbler survey in Guangxi and Yunnan Provinces, China. 
Table 1. Descriptions of each site including whether the Nonggang Babbler was detected during the surveys.

\begin{tabular}{|c|c|c|c|c|c|c|c|c|}
\hline Site & Area $\left(\mathrm{km}^{2}\right)$ & Landform & $\begin{array}{l}\text { Transect } \\
\text { length }(\mathrm{km})\end{array}$ & $\begin{array}{l}\text { Number of } \\
\text { transects }\end{array}$ & $\begin{array}{c}\text { Total } \\
\text { length }(\mathrm{km})\end{array}$ & $\begin{array}{l}\text { Number } \\
\text { of points }\end{array}$ & Survey date & $\begin{array}{l}\text { Nonggang Babbler } \\
\text { presence detected }\end{array}$ \\
\hline $\begin{array}{l}\text { 1. Nonggang site of } \\
\text { Nonggang Nature } \\
\text { Reserve }\end{array}$ & 54.20 & Karst & 6.78 & $6+3^{* *}$ & 61.02 & 117 & $27 / 4-20 / 5 / 2010$ & $\sqrt{ }$ \\
\hline $\begin{array}{l}\text { 2. Longhu site of } \\
\text { Nonggang } \\
\text { Nature Reserve }\end{array}$ & 10.10 & Karst & 3.50 & 6 & 21.00 & $4^{2}$ & $21 / 5-29 / 5 / 2010$ & $\sqrt{ }$ \\
\hline $\begin{array}{l}\text { 3. Longrui site of } \\
\text { Nonggang Nature } \\
\text { Reserve }\end{array}$ & $39 \cdot 40$ & Karst & 6.55 & 6 & $39 \cdot 30$ & 78 & $19 / 4-26 / 4 / 2010$ & \\
\hline 4. Chunxiu & 78.70 & Karst & 9.84 & $6+2$ & 78.72 & 152 & $23-17 / 11 / 2009$ & $\sqrt{ }$ \\
\hline 5. Qinglongshan & 151.00 & Karst & 6.29 & 6 & $37 \cdot 74$ & 72 & $24-28 / 11 / 2009$ & \\
\hline 6. Bangliang & 65.30 & Karst & 8.36 & $6+2$ & 66.88 & 128 & 28/9-8/10/2010 & $\sqrt{ }$ \\
\hline 7. Diding & 9.60 & $\begin{array}{l}\text { Sandstone and shale, } \\
\text { out of the reserve } \\
\text { has karst }\end{array}$ & 3.50 & 6 & 21.00 & $4^{2}$ & $\begin{array}{l}3-8 / 10 / 2010 \\
18-25 / 2 / 2011\end{array}$ & \\
\hline 8. Gulongshan & 296.70 & $\begin{array}{l}\text { Mainly sandstone and } \\
\text { shale, lesser karst }\end{array}$ & 6.19 & 6 & 37.14 & 72 & $\begin{array}{r}30 / 8-8 / 9 / 2009 \\
9-12 / 6 / 2010\end{array}$ & \\
\hline 9. Longhushan & 27.66 & Karst & 3.50 & 6 & 21.00 & $4^{2}$ & $9-15 / 3 / 2011$ & \\
\hline 10. Encheng & 299.00 & Karst & 6.23 & 6 & $37 \cdot 38$ & 72 & $28 / 1-5 / 2 / 2010$ & \\
\hline 11. Xialei & 79.20 & Karst & 4.50 & 6 & 27.00 & 54 & $\begin{array}{l}27 / 2-6 / 3 / 2009 \\
13-15 / 6 / 2010\end{array}$ & \\
\hline 12. Laohutiao & 270.08 & Karst & 6.63 & 6 & $39 \cdot 78$ & 78 & $7-15 / 3 / 2009$ & \\
\hline 13. Bapen & 104.83 & Karst & 5.02 & 6 & 30.12 & 60 & $22-26 / 3 / 2009$ & \\
\hline 14. Banli & 204.36 & Karst & 5.68 & 6 & 34.08 & 66 & $17-21 / 3 / 2009$ & \\
\hline 15. Huanglianshan & 146.00 & $\begin{array}{l}\text { Mainly sandstone and } \\
\text { shale, lesser Karst }\end{array}$ & 5.09 & 6 & 30.54 & 60 & $6-13 / 1 / 2009$ & \\
\hline 16. Xidamingshan & 601.00 & Sandstone and shale & 8.35 & 6 & 50.10 & 96 & $\begin{array}{c}30 / 10-8 / 11 / 2010 \\
16-20 / 3 / 2011\end{array}$ & \\
\hline $\begin{array}{l}\text { 17. Daqingshan } \\
\text { Forestry Farm* }\end{array}$ & 200.00 & Sandstone and shale & 5.56 & 6 & $33 \cdot 36$ & 66 & $10-18 / 11 / 2010$ & \\
\hline 18. Tuoniangjiang & 151.79 & Sandstone and shale & 6.33 & 6 & 37.98 & 72 & $28 / 3-4 / 4 / 2009$ & \\
\hline 19. Gulinjing & 68.52 & Karst & 4.28 & 6 & 25.68 & 48 & $5-9 / 5 / 2011$ & \\
\hline
\end{tabular}

Note: ${ }^{*}$ is the forestry plantation, others are reserves. ${ }^{* *}+3$ means the extra transects have put in to better estimate density, the same as follows. ${ }^{* *}$ these dates cover both the original and subsequent survey. 


\section{Estimating abundance and density}

We increased survey intensity at sites where Nonggang Babbler presence was detected by adding an extra 2-3 line transects to the original six (Table 1 ). In subsequent surveys, all transects were walked again and we recorded the number of Nonggang Babblers observed and the number of observation points. This subsequent survey was repeated twice (Table 1 ). Including a 50-m strip on both sides of the transect, the total area covered was not less than 10\% of the suitable forest area. Density and population sizes were calculated as follows:

$$
\text { Density (D) : } \mathrm{D}=\mathrm{n} / \mathrm{a}
$$

where $\mathrm{n}$ is the number of Nonggang Babblers observed and a is the total area of line transects.

$$
\text { Population size }(\mathrm{N}): \mathrm{N}=\mathrm{D}^{*} \mathrm{~A}
$$

$A$ is the area of forest.

\section{Results}

\section{Distribution and population size}

Nonggang Babblers were observed at four sites, including two in Nonggang Nature Reserve (Nonggang and Longhu), Chunxiu Nature Reserve and Bangliang Nature Reserve (Tables 1 and 2). Since 2008, we have been conducting an ecological study of the babbler at Nonggang Nature Reserve. Despite also being densely vegetated, babblers have never been observed at the Longrui, the third site in Nonggang Nature Reserve. We did not observe babblers at the other 15 sites during our survey. The population size of Nonggang Babbler in these four nature reserves was estimated to be 1,494 individuals (Table 2).

\section{Threats}

The major threats to this species appear to be habitat loss and fragmentation. In the south-west of Guangxi, karst covers about $60 \%$ of the total land area. With the development of the economy, karst forests are continuing to be destroyed and degenerate into thickets, some areas even reverting to rocky deserts. At present, forest only exists in nature reserves. Nonggang NNR is the only national nature reserve in this area, so the vegetation is well protected and the forest is seldom damaged. However, other nature reserves are more degraded and the capacity for conservation management is lower, as the forest is owned by residents living nearby and not the

Table 2. Population size estimates of Nonggang Babbler.

\begin{tabular}{llclc}
\hline Site & Total area km² & Forest area km² & Density km $\mathrm{km}^{-2}$ & $\begin{array}{c}\text { Number of } \\
\text { Nonggang Babbler }\end{array}$ \\
\hline Nonggang & 54.25 & 48.82 & 0.21 & 1,025 \\
Longhu & 10.08 & 9.58 & 0.07 & 67 \\
Chunxiu & 78.70 & 16.46 & 0.04 & 65 \\
Bangliang & 65.30 & 14.93 & 0.09 & 134 \\
Trung Khanh (Vietnam) & 73.79 & 22.56 & $0.09^{*}$ & 203 \\
Total & & & 1,494 \\
\hline
\end{tabular}

*The population of Nonggang babbler in Vietnam Trung Khanh Gibbon Reserve was estimated based on the density recorded in the adjoining Bangliang Gibbon Nature Reserve. 
state, so illegal logging and replanting of economically valuable and other trees for timber and firewood is common. Moreover, the local government supports sheep breeding by residents to improve livelihoods and these animals graze in the forest, damaging the habitat and thus threatening the survival of Nonggang Babbler which is dependent on natural forest.

Except in Nonggang NNR, poaching of species such as Silver Pheasant Lophura nycthemera and White-winged Magpie Urocissa whiteheadi is common, especially during the dry season. When surface water is limited, poachers place traps in pools to capture animals. Nonggang Babbler was often observed walking on rocks and was seldom seen in trees, and may also be vulnerable to trapping.

\section{Discussion}

\section{Habitats}

During the survey we found that many bird species inhabited karst forests. These species are not limited to limestone regions and Nonggang Babbler is the only bird species in China known to be limited to karst forest. We did not find the babbler in the five non-limestone sites or Daqingshan forestry plantation, although we found it in the adjacent Nonggang and Chunxiu sites. The principal habitat of Nonggang Babbler is forest undergrowth, and limestone outcrops, where it forages in gaps between rocks, turning over fallen leaves. The birds were active around rocks, avoided thickets and were seldom found in trees. They were relatively tame when surveyors were quiet and could be approached to $<10 \mathrm{~m}$, so we are confident that if the species was present we were able to obtain an accurate count of the total number of individuals at each point.

We also observed that Nonggang Babbler only nested in gaps or cavities in the limestone in karst forest and we suggest that this species has a restricted range and is endemic to karst forest. Sooty Babbler Stachyris herberti is similar to Nonggang Babbler and is also a restricted-range species in Vietnam (Eames et al. 1995, Robson 2005). Two recently described birds, Bare-faced Bulbul Pycnonotus hualon (Woxvold et al. 2009) and Limestone Leaf Warbler Phylloscopus calciatilis (Alström et al. 2010) were both found in the karst area of northern Vietnam and Lao PDR which is relatively close to south-west Guangxi. Although the Sino-Vietnamese border region is an important area for biodiversity research, only a few bird studies have ever been carried out there.

\section{Distribution and population size}

Despite many forests in south-west Guangxi having similar habitat to Nonggang NNR, only the Chunxiu and Bangliang sites were found to hold Nonggang Babbler. The four sites, including the two new recorded sites and the two sites in Nonggang NNR are all in the Sino-Vietnamese border region. Zhou and Jiang (2008) assumed that Nonggang Babbler was limited to well-protected vegetation in karst areas of south-west China and the limestone region in the northern highlands of Vietnam. Our observations confirmed this assumption.

Bangliang Gibbon Nature Reserve, one of the new sites for Nonggang Babbler, is contiguous with Trung Khanh Gibbon Nature Reserve in Vietnam. We observed Nonggang Babbler in the border forest which is also the habitat of eastern black-crested gibbon Nomascus nasutus and one of our observation points (Laolangdong, $22^{\circ} 55^{\prime} \mathrm{N}, 106^{\circ} 3 \mathrm{O}^{\prime} \mathrm{E}$ ) is less than $30 \mathrm{~m}$ from the SinoVietnamese border. Because the habitats in the two reserves are similar, there seems little doubt that Nonggang Babbler will also occur in Trung Khanh Reserve. The area in Vietnam between Bangliang and Chunxiu may also hold populations of the babbler and further surveys in this area are required.

The Longrui site of Nonggang NNR, where the babbler was not found, has similar vegetation to the Nonggang site, but lies to the east of Zuo River in Longzhou county. Many of the staff of the 
reserve recognised Nonggang Babbler but had not observed it at Longrui. Our survey failed to find the babbler in Longrui or in Gulinjing Nature Reserve to the west of the Dama River (Figure 1 ). The babblers were often seen walking on rocks, were seldom seen flying and flew only short distances when disturbed (Zhou and Jiang 2008). Since their flight ability appears to be very weak, the Zuo and Dama rivers probably form a natural barrier.

Densities were highest in the Nonggang site, while smaller patch area and higher disturbance by local residents may be a cause of the lower densities at the Longhu and Chunxiu sites. The population estimate for Trung Khanh Nature Reserve was extrapolated from densities obtained in Bangliang and the estimated area of eastern black crested gibbon habitat and the estimate may not be accurate.

Although it seems highly likely that Nonggang Babbler is also distributed in Vietnam, we cannot confirm its presence there, as we did not conduct a survey on the Vietnam side of the border. Nonggang Babbler density was estimated from the number of birds recorded during the surveys. This method could be subject to some inaccuracy because playback may attract birds from farther away into the $50 \mathrm{~m}$ area and thus inflate densities. A rigorous estimate of the babbler's population size will require further analysis using remote sensing, GIS and techniques such as maximum entropy modeling, as well as more refined census methodology.

According to current information, the estimated population of Nonggang Babbler is $>2,000$ individuals scattered across four isolated sites (Bangliang and Trung Khanh are combined as one site), and the number at two sites (Longhu and Chunxiu) is below Ioo individuals. These small isolated populations are more vulnerable to extinction.

\section{Conservation measures}

The four sites where the babbler occurs make up a preliminary list of priority sites for its conservation. Determining its distribution in Vietnam is also a priority for this species. Since Nonggang Babbler was discovered, Nonggang NNR has shown a strong commitment to conserve the species. In the light of recent findings, the managements of Chunxiu and Bangliang Nature Reserves have also expressed the intention to increase conservation efforts.

The distribution of Nonggang Babbler is fragmented, its population size is small and habitat loss is a serious threat. We urge that no further specimens are taken from the wild. To reduce the risk of extinction, all sites where the species occurs should cooperate with each other and establish corridors of forested habitat to promote the movement of individuals between remaining habitat patches. Effective conservation at these sites will call for a combination of community development, habitat management and law enforcement. Reduction in hunting, illegal logging and grazing in the forests would all benefit this species.

The survey showed that Nonggang Babbler is a bird typical of karst forest and foraging and nesting is entirely dependent on this habitat. The karst environment is fragile, very sensitive to human impact, and restoration is impossible once destroyed (Tuyet 2001). We suggest that the species should be added to the China State Key Protected Animal List as soon as possible, and highlight that urgent steps and resources are needed to conserve it. We hope that this effort may contribute to saving Nonggang Babbler from extinction.

\section{Acknowledgements}

The study was financed by the National Nature Science Foundation of China (Grant Nos. 30970381, 31172123). We thank the Forestry Departments of Guangxi Zhuang Autonomous Region and Yunnan Province for their support and collaboration. Field assistance and logistic support were provided by the staff of all the reserves and forestry farm management. The area data of Vietnam Trung Khanh Gibbon Nature Reserve were provided by FFI Beijing Office. We also thank L. Dong, J. Guangwei, X. Liang, W. Yinghuan, M. Yuanjun, and C. Tianbo for their help with field work. 


\section{References}

Alström, P., Davidson, P., Duckworth, J. W., Eames, J. C., Trai, T. L., Cu, N., Olsson, U., Robson, C. and Timmins, R. (2010) Description of a new species of Phylloscopus warbler from Vietnam and Laos. Ibis 152: 145-168.

Antongiovanni, M. and Metzger, J. P. (2005) Influence of matrix habitats on the occurrence of insectivorous birds species in Amazonian forest fragments. Biol. Conserv. 122: 441-451.

Eames, J. C., Lambert, F. R. and Nguyen, $\mathrm{Cu}$ (1995) Rediscovery of the Sooty Babbler Stachyris herberti in central Vietnam. Bird Conserv. Internatn. 5: 129-135.

IUCN (2010) IUCN Red List of threatened species. (www.iucnredlist.org).

Parker, T. A. (1991) On the use of tape recorders in avifaunal surveys. Auk 108: 443-444.

Robson, C. (2005) Field guide to the birds of Southeast Asia: Thailand, Peninsular
Malaysia, Singapore, Vietnam, Cambodia, Laos, Myanmar. London, UK: New Holland.

Summers, R. W. and Buckland, S. T. (2010) A first survey of the global population size and distribution of the Scottish Crossbill Loxia scotica. Bird Conserv. Internatn. 11: 1-13.

Tuyet, D. (2001) Characteristics of karst ecosystems of Vietnam and their vulnerability to human impact. Acta Geol. Sinica 75: 325-324.

Woxvold, I. A., Duckworth, J. W. and Timmins, R. J. (2009) An unusual new bulbul (Passeriformes: Pycnonotidae) from the limestone karst of Lao PDR. Forktail 25: $1-12$.

Zhou, F. and Jiang, A. W. (2008) A new species of babbler (Timaliidae: Stachyris) from the Sino-Vietnamese border region of China. Auk. 125: 420-424.

\section{ZHAOTIAN, ZHOU FANG*, LU ZHOU, YANG GANG, YU CHENXING}

College of Animal Science and Technology, Guangxi University, Nanning, Guangxi 530005, P. R. China.

JIANG AIWU

School of Life Sciences, Lanzhou University, Lanzhou, Gansu 730ooo, P. R. China.

*Author for correspondence; e-mail: zhoufang@gxu.edu.cn and zhoufang768@126.com

Received 2 July 2011; revision accepted 16 February 2012;

Published online 28 January 2013 